TABLE I.-Oxyuris.

\begin{tabular}{|c|c|c|c|c|c|c|c|c|}
\hline & 离 & $\begin{array}{l}\dot{D} \\
\dot{d} \\
\ddot{D}\end{array}$ & 客。 & 递兽 & 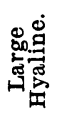 & 递㻤 & 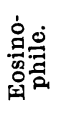 & 悹富 \\
\hline J. E. & 8 & M. & 12.9 & 3.8 & 3.8 & 64.8 & 13.7 & r.o \\
\hline c. $\mathbf{E}$ & 6 & M. & $\mathrm{x} 9.6$ & 16.8 & $\begin{array}{l}3.0 \\
\text { r. }\end{array}$ & 48.6 & 12.8 & 06 \\
\hline A. S. & 7 & M. & 33.6 & 9.6 & 4.4 & 42.6 & 9.6 & 0.2 \\
\hline S. & 7 & $\mathbf{M}$. & 20.2 & 9.8 & 4.8 & 54.8 & 9.2 & I. 2 \\
\hline R. U. & $3^{\frac{2}{2}}$ & F. & 23.4 & 7.6 & 3.2 & 57.0 & 8.6 & 0.2 \\
\hline M. & 3 & F. & 38.2 & 12.2 & 5.8 & 35.8 & 7.4 & 06 \\
\hline V. H. & $2 \frac{1}{4}$ & $\mathrm{~F}$. & 43.0 & 6.6 & 4.8 & 39.4 & 6.2 & 0.0 \\
\hline J. H. & 10 & M. & I7.4 & 7.0 & 4.4 & 63.8 & 6.2 & I. 2 \\
\hline M. & 2 & M. & 35.8 & 10.3 & 6.1 & 42.9 & 4.8 & 0.6 \\
\hline M. & 4 & M. & 39.6 & 90 & 3.6 & 43.0 & 4.6 & 02 \\
\hline J. & 4 & F. & $5 \mathrm{I} .4$ & 7.2 & 2.6 & 34.4 & 4.2 & 0.2 \\
\hline$P$. & 12 & $\mathbf{F}$. & 33.2 & 7.6 & 4.4 & 50.0 & 4.2 & 0.6 \\
\hline$\overline{\mathbf{W}}$. & $3^{\frac{1}{2}}$ & $\mathbf{F}$. & 31.2 & 8.2 & 6.4 & 50.2 & 3.8 & 0.2 \\
\hline M. & $\mathbf{x}_{4}^{\frac{1}{4}}$ & F. & 33.2 & 13.2 & 6.2 & 43.6 & 3.6 & 0.2 \\
\hline B. & 7 & F. & 44.8 & 6.9 & $4 \cdot 3$ & 40.4 & 3.6 & 0.0 \\
\hline S. & 6 & $\mathbf{F}$ & 41.8 & 4.2 & 6.2 & 44.4 & 3.0 & 0.4 \\
\hline V. & 4 & M, & 34.6 & ro.8 & 32 & 48.8 & 2.6 & 0.0 \\
\hline R. & 2 & $\mathrm{~F}$ & 46.2 & 7.8 & 6.2 & $3^{8.2}$ & 1.4 & 0.2 \\
\hline A. $\mathbf{P}$. & 18 & M. & \multirow{2}{*}{\multicolumn{2}{|c|}{$\begin{array}{l}23.8 \\
23.0\end{array}$}} & 2.1 & 73.0 & I. I & 0.0 \\
\hline A. $\mathbf{P}$ & & & & & 4.2 & 71.8 & 0.4 & 0.6 \\
\hline
\end{tabular}

more than 6-that is, a distinct increase--while 36 per cent. are less than 4 per cent. In less than half the cases, therefore, is any indication of diagnostic importance found in the blood examination. Indeed, it may be that the number of positive results should be considered to be lower even than this, since an eosinophilia may occur in children without any apparent cause. Zappert ${ }^{2}$ was the first to call attention to this point, and for normal children gives 46 blood counts where the numbers of eosinophiles as a whole far exceed those recorded here, reaching in one instance the remarkable figure of 19 per cent. Zappert does not, however, exclude or take into consideration the question of worms, and it is at least not improbable that some, at any rate, of his children were infected with parasites. The experience of other ob servers has not confirmed the very high figures given by rappert, though the fact that sporadic eosinophilias do occur in children has been confirmed. Table II. gives the percentage of eosinophiles in ro consecutive cases of normal and (as far as could be ascertained) wormless children :

TABLE II.

\begin{tabular}{|c|c|c|c|c|c|}
\hline Age. & Sex. & Eosinophiles. & Age. & Sex. & Eosinophiles. \\
\hline $\begin{array}{l}4 \\
5 \\
3 \\
4 \\
5\end{array}$ & $\begin{array}{l}\text { M. } \\
\text { M. } \\
\text { F. } \\
\text { M. } \\
\text { M. }\end{array}$ & $\begin{array}{l}\% \\
\% .0 \\
0.6 \\
1.6 \\
2.8 \\
3.0\end{array}$ & $\begin{array}{l}\frac{1}{2} \\
5 \frac{1}{2} \\
2 \frac{\frac{3}{4}}{4} \\
5 \\
3\end{array}$ & $\begin{array}{l}\mathbf{F} . \\
\mathbf{F} \\
\mathbf{M} . \\
\mathbf{F} . \\
\mathbf{F} .\end{array}$ & $\begin{array}{c}\% \\
3.0 \\
3.2 \\
4.8 \\
5.2 \\
5.4\end{array}$ \\
\hline
\end{tabular}

It seems, then, to be clear that in the present series children who harbour oxyuris have definite increase of eosinophiles in about two-fifths of the cases.

Table III gives a few results of the blood counts for other varieties of worms : TABLE III.

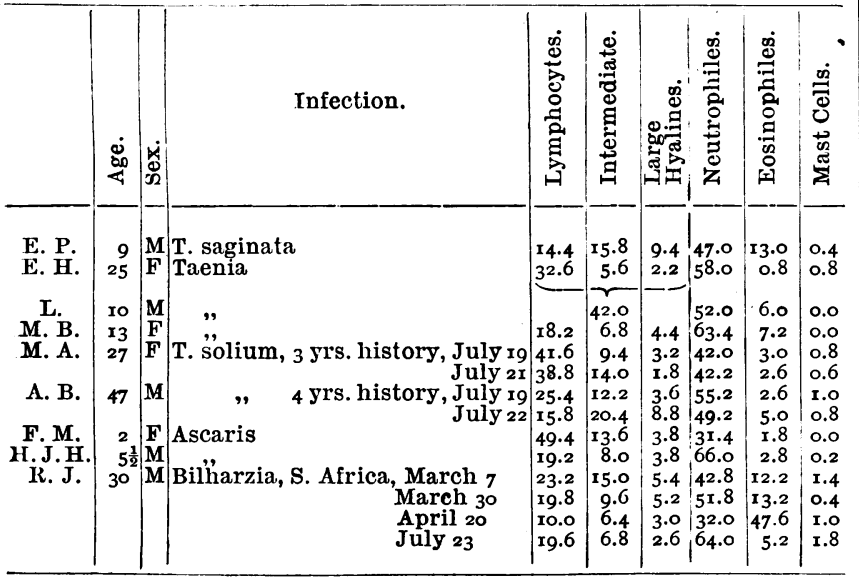

The case of bilharzia (haematuria only present) had much improved, and only occasional ova could be found when the percentage of eosinophiles rose to 47.6 ; later on, when the count had fallen nearly to normal, eggs were still present in the urine, though there had been no blood for some time. In neither of the cases of ascaris was any eosinophilia present. ${ }^{3}$ Three of the six cases of tapeworms show some increase ( 6 to 13 per cent.), but the three cases in adults show normal counts.

An explanation of the irregular occurrence of an eosinophilia in these worm infections may possibly be found in the length of time for which the worm has been present. I have shown for ankylostoma ${ }^{4}$ that the greatest leucocytic reaction occurs soon after infection, and after a time wears off without the worm leaving the intestine. The same may well be true for oxyuris and taenia, though here it is impossible to ascertain the date of infection, even approximately. Two of the present cases of taenia infection had long histories. On the other hand, the variation may be due to individual predisposition, and may possibly be connected directly with age, as some of these results suggest.

There is nothing further remarkable in any of the counts except that in some cases the mast cells reach a rather high figure. In the oxyuris cases there are three counts of I per cent or more. The cases with an eosinophilia of more than 6 per cent. have an average for mast cells of 0.62 per cent., while those with less than 4 per cent. eosinophiles only reach 0.26 per cent. mast cells. The association is also seen in the case of bilharzia (eosinophiles 19.5 per cent., mast cells, I.15 per cent.), and in the two cases of T. solium, though there is no eosinophilia, the counts of mast cells are rather high.

For two of the cases here recorded I am indebted to Dr. H. S. D. Browne and Dr. C. G. Seligman.

NOTES AND REFERENCES. 1 The figures of Bucklers (Miinch. med. Woch., xli. r894, p. 22) are classical,
but refer largely to mixed infections. 2 Zeit. f. klin. Med., xxiii, p. 244, 1893. 3 Has a case of pure trichocephalus infection with an eosinophilia been recorded? 4 Journal of Hygiene, vol. iii, rgo3, p. 121.

\section{THE ETIOLOGY OF BERI-BERI.}

BY W. GILMORE ELLIS, M.D.

Medical Superintendent, Government Asylum, Singapore.

In this asylum beri-beri has been endemic since shortly after its opening in 1887 , the deaths from the disease averaging 45 per annum and the number of cases treated about 150 per annum for the five years ending I900 out of an average daily number of 207. Since that date the disease had been nearly stamped out. Our numbers having considerably fallen it has been possible to move the patients at every few days' interval from one part of the asylum to another, thoroughly cleaning and disinfecting up behind as we move; more attention has been paid to the disinfection of clothes, bedding, furniture, single rooms, etc., and the ventilation and drainage have been recently improved. Above all, three years ago, two small wards were constructed on the sea beach four miles from town, and here all cases have been sent upon showing the slightest symptoms of beri-beri. These wards are washed out, walls included, in sea water, and then in a solution of mercury perchloride weekly. All woodwork is frequently whitewashed or tarred. The bed boards are soaked in sea water and dried in the sun twice a week. All clothing, bedding included, is changed and disinfected twice a week. The whole compound, consisting of sand, is raked over weekly, and thus thoroughly exposed to the rays of the sun, and from time to time the surface sand is collected and put on the beach below high water mark for a tide and then returned. All patients are bathed for at least half an hour daily, and are kept in the open during the whole day. Massage is used in all cases. The administration of strychnine, digitalis, iron, and very free purgation is the common medical treatment. To these precautions our present immunity from the disease-12 cases to date for the year and but 5 deaths in the last two years-is, in my opinion, due. One of these 5 deaths occurred in the seaside hospital, the other 4 patients were too maniacal to be sent there for treatment. Our patients, I may add, are all fed on Siamese rice.

Thirteen years ago I separated twenty healthy native patients on admission in two cottage blocks, giving them European food and no rice whatever. At that time beriberi was very prevalent among the natives-we have never had any cases in Europeans or Eurasians-and I wondered 
if in any way the food was in fault. My experiment had to be given up in less than three months, as more than half of the twenty cases had by then developed symptoms of the disease. The opinion I then came to was that beri-beri was a place disease, that the soil and buildings were infected, and that people dwelling there were liable to absorb the poison, whatever it was, that this poison absorbed in sufficient quantities was the cause of beri-beri, and this opinion I have never seen reason to change. From that date disinfection has lately been relied on to combat the disease, and I can only regret that the more thorough manner in which we now try to carry it out was not adopted earlier.

An instructive instance of a small epidemic of beri-beri on shipboard came under my notice in 1900, entirely, I think, putting Siam rice out of the question as a cause of beri-beri. A well-found steamer carrying 28 Malay and 5I Chinese hands, sailed from Singapore for New Zealand and Australian ports. All were fed on Siam rice cooked in the same manner and in one galley. When in cold weather near New Zealand, beri-beri broke out in the starboard forecastle inhabited by 14 of the Malays, and in all there were 8 cases and 5 deaths. This forecastle had the galley situated immediately aft with but a thin wooden partition between. The heat from the galley caused the cabin to be always sweating and steamy, as it was somewhat wet from the bad weather experienced at the time ; in fact converted it into a perfect incubation chamber. Such a condition has been noted many times as favourable to the spread of the disease. No food was taken to or consumed in the forecastle.

I was consulted by wire as to any precautionary steps that could be taken, and recommended the erection of shelters on deck to accommodate the hands occupying the forecastle, the thorough disinfection of the ship. paying special attention to the starboard forecastle, which should not be used for habitation during the remainder of the voyage, and some ordinary medicinal treatment. On the ship's arrival at Melbourne the 3 sick were sent to hospital, where they recovered; 5 had died, and no further case had occurred, nor did one. Had the rice been in fault it is difficult to understand why the 8 cases occurring should have all been among 14 men occupying one cabin, and that the remaining 65 hands should have entirely escaped.

\section{THE PHYSICAL FACTORS IN PHOTOTHERAPY.}

$$
\begin{array}{r}
\text { BY J. E. BARNARD and } \begin{array}{r}
\text { H. IF R. MORGAN, } \\
\text { M.A.Oxon., M.R.C.S.Eng. } \\
\text { L.R.C.P.Lond., D.P.H.Camb }
\end{array} \\
\text { [From the Lister_Institute of Preventive Medicine.] }
\end{array}
$$

THESE investigations have been made with a view to ascertain to what agencies we may attribute any therapeutic effects that the light treatment may produce. To obtain exact experimental data on this subject would place the light treatment in a more satisfactory position, for despite the results recorded the methods may be said to be somewhat empirical.

One of the first questions that arise in considering the effect of the light treatment on any specifie disease, such as lupus, is whether the result produced is due to bactericidal power of the light, or to the reaction which it excites in the tissues themselves. In other words, are the tubercle bacilli in lupus destroyed, or at any rate prevented from multiplying, by the direct action of the light, or does the tissue reaction caused by the light set up a condition inimical to the growth of the bacilli?

We have as yet no certain answer to this question. That light, without heat, destroys micro-organisms outside the body is well known, as the rèsults of numerous experiments by many observers, and their results we have verified in the most conclusive way, as will be subsequently shown. But that bacteria lying inside the tissues of the body can be destroyed by the action of light is a matter of considerable doubt. Light is, in the first place, powerless to destroy bacteria in those cases where its rays are made to pass through any organic substance before impinging on the bacteria, even the thinnest film of agar, for instance, serving as a protection. Much less can the bactericidal rays in light penetrate living or dead tissue under the ordinary conditions of experiment. This statement has been proved in the following way:

The light from an automatic arc lamp, that is a lamp in which the carbon electrodes were kept at a suitable distance by means of a clockwork arrangement, was allowed to pass through metal cylinder, through which water continually circulated in order to eliminate heat, and which was closed at each end with a disc of quartz. An agar plate thickly inoculated in the usual way with an active culture of bacillus coli communis was exposed to the light directly after inoculation, and then incubated for twenty-four hours or longer at $37^{\circ} \mathrm{C}$. The light was only allowed to fall on a portion of the plate, so that on the other portion, unacted on by the light, the organisms should grow normally and serve as a control. A current was used of 7 ampères at a distance of $10 \mathrm{~cm}$. from the arc. It was found that when exposed for as short a time as eleven seconds, the comparative number of surface colonies was greatly reduced, but that those in the depth were unaffected. The deep colonies were unaffected even after two hours' exposure to the light under the same conditions.

Again a portion of human skin, in one instance the cortical layer, in another the subcutaneous cellular tissue, was placed on the quartz disc of the apparatus before montioned, covering it entirely. An agar plate on which had been spread, with a sterilized brush, an active culture of bacillus coli communis, was so placed that the light from an arc fell on it after passing through the water-circulating apparatus and the human skin. After two hours' exposure, and whatever the current used, no effect was produced on the bacilli, as on incubating the plate at $37^{\circ} \mathrm{C}$. for twenty-four hours, the resulting growth was found to be equally vigorous over the entire surface of the plate. The same experiment was conducted with a living and a dead frog's foot, interposed in the same

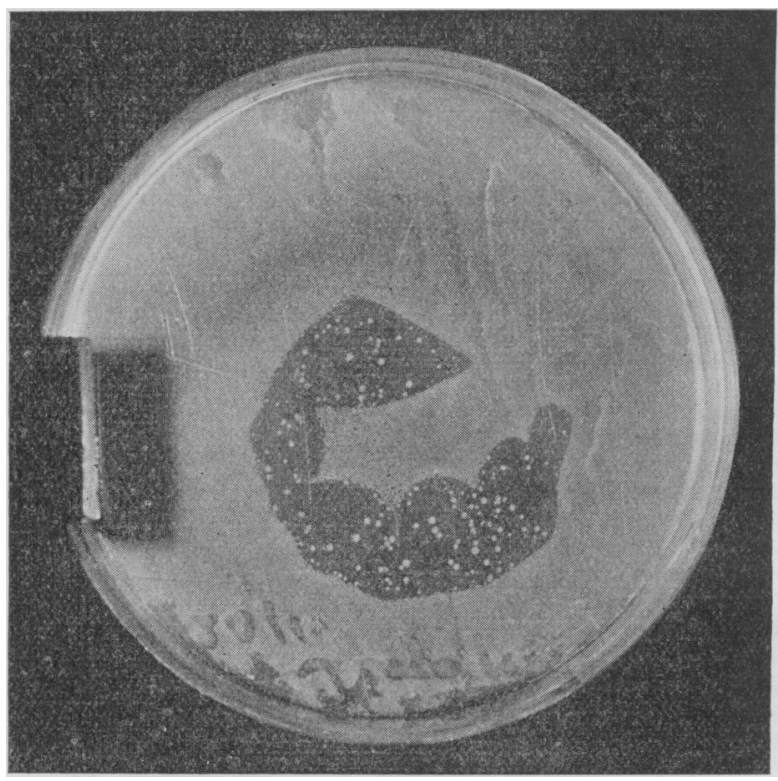

Fig. I.-Experiment with dead frog's foot.

way as the human skin, and with equally negative results.

The light passing at the side of the frog's foot produced the effect reproduced in the figure, namely, a destruction of almost all the surface bacilli, while those protected by the semitransparent webbing of the foot grew normally. The reason why all the colonies on the surface of the agar are not destroyed even where the unobstructed light falls on them is still undetermined. It is perhaps possible that some few of the organisms, during the process of inoculation, have been introduced under the surface. and not being strictly superficial, are protected by an overlying absorbent film of agar. From these experiments we are therefore led to conclue that, the bactericidal rays being non-penetrative, the therapeutic effects of light may possibly be due to the reaction produced in the tissues by the light rather than to the direct bactericidal action of the rays themselves. Our next object was to differentiate, if possible, between the rays which are bactericidal and the rays which excite a reaction in living tissues.

In this we have up to the present been only partially successful. Whilst we have been able to find in the spectrum the exact position of the bactericidal rays, those causing the reactionary effect on tissue are still unlocalized, at least with any certainty. With the object of determining the most aciively bactericidal rays among those produced by a continuous current arc, some superficially inoculated plates were exposed to the spectrum as transmitted by a spectroscope with 